\title{
Instructions for Radiological Case Reports
}

\section{Anleitung zum Schreiben eines radiologischen Fallberichts}

\author{
Author \\ Peter Bannas

\begin{abstract}
Affiliation und Nuklearmedizin, Universitätsklinikum Hamburg-Eppendorf, Hamburg, Germany

Department of Diagnostic and Interventional Radiology and Nuclear Medicine, University Medical Center, Hamburg-Eppendorf, Germany
\end{abstract} \\ Klinik und Poliklinik für Diagnostische und Interventionelle Radiologie
}

Key words

case report, instructions, radiology

received 18.10.2016

accepted 23.12.2016

Bibliography

DOI http://dx.doi.org/10.1055/s-0043-101525

Published online: 2017 | Fortschr Röntgenstr 2017; 189: 333-337

(c) Georg Thieme Verlag KG Stuttgart · New York

ISSN 1438-9029

Correspondence

Dr. Peter Bannas

Diagnostikzentrum, Klinik und Poliklinik für Diagnostische und

Interventionelle Radiologie, Universitätsklinikum Hamburg Eppendorf Department of Diagnostic and Interventional Radiology and Nuclear Medicine, University Medical Center, Hamburg-Eppendorf, Germany Martinistraße 52

20246 Hamburg

Germany

Tel.: ++ 49/40/741054023

Fax: ++49/40/74106799

P.bannas@uke.de

\section{ABSTRACT}

Purpose This paper explains the purpose and structure of a radiological case report and provides guidance for radiologists with respect to the writing of a well-structured patient case report.

Materials and Methods The current literature and the author's experience as a writer were used to create a manual that describes steps for preparing a radiological case report containing all of the important ingredients for effective communication.

Results Case reports are the first line of evidence in documenting clinical observations in the literature. A case report should be written succinctly and consists of four structured main sections: introduction, description of the case, discussion and conclusion. Its structure follows the structure of an original research article, whereby the description of the case of the case report corresponds to the materials and methods section of the research article. The introduction provides the subject and merit of the case report with respect to the published literature. The case description presents the case in detail and chronological order to allow for plausibility. The discussion compares the case with the published literature and summarizes the essential features. A case report, like an original article, must provide a justified conclusion. The conclusion should be brief and be applicable to clinical practice.

Conclusion The unique quality of the case, proper preparation and a clear conclusion are essential for a case report to be published.

\section{Key Points:}

- Case reports are the first line of evidence in documenting clinical observations in the literature

- The structure of a case report structure follows the structure of an original research article

- The unique quality of the case, proper preparation and a clear conclusion are essential for a case report to be published.

\section{Citation Format}

- Bannas P. Anleitung zum Schreiben eines radiologischen Fallberichts. Fortschr Röntgenstr 2017; 189: 333-337

\section{ZUSAMMENFASSUNG}

Ziel Basierend auf der aktuellen Literatur und der Erfahrung des Autors wird eine Anleitung zum Verfassen eines strukturierten Fallberichts gegeben.

Ergebnisse Fallberichte sind eine wichtige Quelle für neue und ungewöhnliche klinische Beobachtungen in der medizinischen Literatur. Sie sind kurz und prägnant verfasst und bestehen aus vier strukturierten Hauptabschnitten: Einleitung, Fallbeschreibung, Diskussion und Schlussfolgerung. Der Textaufbau folgt exakt der Struktur einer wissenschaftlichen Originalie, wobei die Fallbeschreibung des Fallberichts dem Methoden- und Ergebnissteil einer Originalie entspricht. Die Einleitung liefert die Begründung für die Erstellung des Fallberichts und relevante Hintergrundinformationen. Die Fallbeschreibung beschreibt die Kasuistik chronologisch und mit allen notwendigen Details, um eine klare Nachvollziehbarkeit zu ermöglichen. In der Diskussion werden die Besonderheiten der vorgestellten Kasuistik herausgearbeitet und der bereits publizierten Literatur kritisch gegenübergestellt. Zu einem Fallbericht gehört, ebenso wie zu einer Originalie, eine klare Schlussfolgerung, diese sollte kurz gefasst sein und einen konkreten klinischen Bezug aufweisen.

Schlussfolgerungen Die Einzigartigkeit des Falles, eine sorgfältige und strukturierte Präsentation, sowie eine klare Schlussfolgerung sind entscheidend für die erfolgreiche Publikation.

\section{Introduction}

The purpose of a clinical case report is to publish new insights acquired on the basis of an individual medical case. It is a detailed description of observations and measures related to a single patient. The report describes an unusual case and its clinical picture, course, diagnosis, and treatment [1]. Important observations that are overlooked or not recorded in clinical studies can be made based on case reports. These observations can contain insights that expand our medical knowledge or act as an impetus 
for new research [2, 3]. In fact, many medical innovations and developments come from case reports, such as in the case of the first heart transplantation [4].

Observation of a rare disease or an unusual clinical picture of a common disease is the first requirement for creating and successful publishing a case report. Case reports with compelling figures in the form of photos or radiological images are particularly suitable for successful publication [5]. However, a radiological case report should not be used simply to present a particularly impressive image but rather must clearly communicate which medical insights and conclusions can be gained from the case.

Nonetheless, the majority of radiological case reports submitted for publication lack a clear conclusion. Moreover, many submitted case reports contain technical and editorial errors [6]. As a result, interesting but poorly written case reports are rejected by peer-reviewed journals [3]. In summary, the uniqueness of the case, a careful and structured presentation, and a clear conclusion are essential for successful publication $[3,7]$. The present study is intended to provide instructions for writing clearly structured radiological case reports.

\section{Structure of a radiological case report}

Every case report employs a systematic format which follows the same basic structure as all scientific publications:

1. Title

2. Abstract (RöFo: not required)

3. Introduction

4. Description of the case (= materials and methods)

5. Discussion

6. Conclusion (RöFo: core statements)

7. References (RöFo: in-text citations)

8. Figures

Of course, this basic structure can vary from journal to journal. Therefore, it is necessary to become acquainted with the guidelines of the journal to which you intend to submit your case report and structure your manuscript accordingly. The most important elements of a case report are the description of the case, discussion and conclusion [5]. Together with the introduction these elements form the core of a case report and each of these sections must contain the correct content according to its function in the report. Compelling figures illustrate the most important information and improve the understandability of a case report [2].

The structure of a case report does indeed correspond exactly to the structure of an original research article $[8,9]$ with the description of the case of the case report corresponding to the materials and methods section of an original article. This parallel shows that a case report, just as an original article, must include a clear conclusion.

\section{What should be written down and when?}

Before beginning to write, it is important to clearly define the insights gained from the case. What is special about the case?
What can be learned from the case? Which concrete conclusions can be drawn?

Begin with a comprehensive search of the literature. It is important to identify and analyze all relevant articles [5]. Has your case already been described in the literature? If yes, your own case report should only be written if you can show relevant differences with respect to the previously published case reports resulting in an additional gain in information and a unique conclusion.

It is recommended to formulate a working title based on the presented case and the conclusion. This provides the central theme for the entire manuscript [8]. Next, it is advisable to preselect figures since these play a central role in radiological case reports and also define the central theme for the manuscript. Write a summarizing legend for each figure. If the working title and the figures with their legends provide a central theme leading to a conclusion, it is time to write the case report [10].

It is easiest to begin with the description of the case. This section requires the clinical information and prepared figures that define the central theme [10]. The introduction can then be written. Introduce your case with literature references that are as current as possible to emphasize the relevance of the presented case. Now the discussion can be written to connect the description of the case to the introduction.

The abstract, which serves as a synopsis of the entire manuscript, is then written. A final title providing the best possible description of the case report can be formulated in the last step.

Case reports should be as short as possible. RöFo allows a maximum of 6000 characters for a case report [11]. A short, precise, and concise article can be achieved by repeatedly revising a manuscript [8]. Moreover, repeated revisions improve readability and understandability.

\section{Recommendations regarding the structure of the individual sections}

The following explains the purpose and structure of each individual section of a radiological case report. - Table 1 provides an overview in the form of a checklist. The sequence of the explanations corresponds to the chronological sequence of the sections in the case report, not to the sequence in which these sections should be written.

\section{Title}

The title should be a concise summary of the case and arouse the interest of readers [7, 8]. It must clearly indicate that the article is a case report. "Case report" or "case study" should ideally appear in the title [6]. All relevant features of the case must be specified: The disease, its clinical uniqueness or new clinical aspect, and, in the case of a radiological case report, the imaging method. Combining two sentences with a colon strengthens the statement while allowing short formulations, for example: "Medial fracture of the femoral neck in Klippel-Trenaunay syndrome: CT angiography essential for treatment" [12]. The central role of imaging is highlighted in this example. Alternatively, a concise, positive statement regarding the most important result can 
- Table 1 Checklist: Order, purpose, and content of the individual sections of a radiological case report.

\begin{tabular}{|c|c|c|}
\hline section & purpose and content & completed \\
\hline \multirow[t]{3}{*}{ Title: } & the title provides an accurate and succinct summary of the case & $\square$ \\
\hline & - special feature of the disease & $\square$ \\
\hline & - role of imaging & $\square$ \\
\hline \multirow[t]{3}{*}{ Abstract: } & the abstract highlights the originality and relevance of the case & $\square$ \\
\hline & - structured: Introduction, description of the case, discussion, conclusion & $\square$ \\
\hline & - concise synopsis of the case & $\square$ \\
\hline \multirow[t]{3}{*}{ Introduction: } & the introduction describes the reason for the creation of the case report & $\square$ \\
\hline & - background information that is relevant for understanding the case & $\square$ \\
\hline & - presentation of the relevant literature & $\square$ \\
\hline \multirow[t]{4}{*}{ Description of the case: } & the description of the case accurately describes the case & $\square$ \\
\hline & - sufficient details for clear plausibility and comparability & $\square$ \\
\hline & - chronological & $\square$ \\
\hline & - objective & $\square$ \\
\hline \multirow[t]{7}{*}{ Discussion: } & the discussion addresses the special features of the case & $\square$ \\
\hline & - concrete new insights and therapeutic consequences & $\square$ \\
\hline & - comparison to previously published literature & $\square$ \\
\hline & - applicability to the clinical routine & $\square$ \\
\hline & - alternative imaging modalities & $\square$ \\
\hline & - differential diagnoses & $\square$ \\
\hline & - limitations & $\square$ \\
\hline \multirow[t]{3}{*}{ Conclusion: } & the conclusion should be applicable to clinical practice & $\square$ \\
\hline & - sound, substantiated by literature discussed above & $\square$ \\
\hline & - concise, clear, and plausible & $\square$ \\
\hline References: & references are relevant and current & $\square$ \\
\hline \multirow[t]{4}{*}{ Figures: } & the figures are compelling and best illustrate the case & $\square$ \\
\hline & - can be understood without the main document & $\square$ \\
\hline & - highlighting of relevant findings & $\square$ \\
\hline & - complete legends & $\square$ \\
\hline \multirow[t]{4}{*}{ General information: } & the case report is short and concise & $\square$ \\
\hline & - finalized by careful and repeated revision & $\square$ \\
\hline & - clear structure and chronological presentation & $\square$ \\
\hline & - compliance with the requirements of the journal & $\square$ \\
\hline
\end{tabular}

be formulated, for example: "Successful fluoroscopy-guided placement of a percutaneous gastrostomy tube in a stomach having previously undergone Billroth II" [13]. Such formulations are memorable and capture the attention of readers.

\section{Abstract}

The abstract is a brief structured synopsis of the case report. Such an abstract is not required for RöFo [11] but is required in numerous other journals. The abstract determines whether a case report can be found via PubMed or other search engines. Moreover, it allows readers to determine whether they want to read the entire case report [14]. Therefore, the originality and relevance of the case report should be described in a concise manner in the abstract.

The abstract should be short [2]. It is usually limited to 150 to 250 words. The abstract should contain a condensed version of the same sections as the main text: Introduction, description of the case, discussion, and conclusion. Depending on the requirements of the particular journal, the abstract is divided into these four sections or is comprised of a single coherent paragraph.

At any rate, it should include one or two sentences that introduce the case followed by a short description of the case and one or two sentences discussing the case. The abstract ends with a conclusion. 


\section{Introduction}

The introduction describes the reason for the creation of the case report. As a rule, it should be limited to one paragraph.

The introduction provides the necessary background information to put the presented and discussed case in the right context. The relevance of the case is established on the basis the current literature to arouse the interest of readers. The diagnostic or interventional problem with respect to the disease in question can be illuminated here. Indicate how the subsequently presented case will expand current knowledge. However, do not discuss significant details as to how your case differs from the previously published case reports. This is first addressed in the discussion section. The presented patient case is then briefly summarized in one sentence, for example: "We report on a patient with...". This allows a transition to the next section, i. e., the actual description of the case.

\section{Description of the case}

The description of the case is an integral part of the case report and provides the actual description of the case. The course of the disease and the management of patient treatment should be objectively described here. The description of the case must be written in chronological order. All necessary details must be described in order to allow for plausibility. This allows the reader to objectively assess the significance of the case report [3]. This section is typically comprised of three paragraphs.

Patient-specific data such as age, sex, relevant preexisting conditions, and lab values (including standard ranges), and other relevant clinical parameters are described in the first paragraph. Providing this data makes it possible to compare to other cases with the same clinical picture. Only data that is relevant for the case is necessary.

The actual disease and its clinical picture, course, diagnosis, and treatment are described in the second paragraph. Figures as well as technical imaging information are included in this section. At what point in the disease was diagnostic or interventional imaging performed? Which imaging modality was used? This includes an exact description of the examination technique, e. $g$. use of contrast agent or the type of MRI sequences. In the case of interventional procedures, all instruments that were used, such as catheters, guide wires, stents, or embolization materials, must be clearly identifiable [13]. Objectively describe how the imaging method that was used influenced the course of the disease. However, the role of imaging should not be discussed or evaluated here. Interpretation is performed in the following discussion.

The last paragraph of the description of the case discusses the further course of the disease, whether the patient was able to be successfully treated, and the health of the patient at the time of the creation of the case report.

\section{Discussion}

The discussion section is the most important section of the case report. The case is described, discussed, and commented on here. Above all, the special features of the presented case should be described and compared to the previously published study results and case reports. Moreover, the newly acquired insights should be given particular emphasis and their potential transferability to the clinical routine should be discussed [2, 3]. The discussion section should focus on your own case. Avoid circuitous discussions of other sources. The discussion should be limited to three to five paragraphs.

Begin with a short summary of your own case. Then compare the special features of your case to the literature cited in the introduction. Contradictions should be pointed out and discussed. These observations may be the most interesting results. Reviewers and editors must be convinced of the uniqueness of your case at this point

In a radiological case report, the role of imaging must be discussed. In particular, the influence of the diagnostic method or intervention on the disease should be determined. Moreover, the advantages and disadvantages of potential alternative imaging modalities, e.g. the use of MRI instead of CT, should be discussed. The radiological findings should also be examined. Which differential diagnoses need to be considered in the case of the determined diagnoses?

The determination of the most important new radiological and medical insights is of utmost importance for the quality and relevance of a case report. Describe how the case affected your clinical routine and patient care. If, for example, a method was implemented in your own department based on the new insights, this should be documented here. However, due to the unique constellation of each case report, the newly acquired insights should not be generalized. Therefore, support your statements with citations from the literature and avoid overestimation of your observations [3].

Moreover, the limitations of a case report must always be discussed in the following [15]. An important and common limitation is typically the retrospective data acquisition. Specification and critical discussion of these and other limitations demonstrate that the subsequent conclusion can be made objectively and impartially.

The uniqueness and the essence of the case report are summarized in the final paragraph. This allows transition to the last section, i. e., the conclusion.

\section{Conclusion}

Formulate a sound and concrete conclusion that is based on the insights provided in the discussion and relates to the introduction [3]. The conclusion should be applicable to clinical practice. This section should not exceed one paragraph and should be limited to three or four key statements [2]. Such a conclusion is not required for RöFo. Instead three bulleted key points at the end of the article are required as an equivalent [11].

\section{References}

Cite the most relevant literature including historically significant publications ("seminal papers") and current publications to emphasize the currentness and relevance of your own case report $[16,17]$. The identification and referencing of current publications is of particular importance since radiology is characterized by rapid technical progress. 
Literature from journals with peer-review procedures should be cited as sources. The number of references in radiological case reports should be limited to 5 - 10. A maximum of 5 references is allowed in RöFo and these are integrated as in-text citations [11]. Format the literature citations according to the requirements of the journal. The use of a reference management program, e. g. Endnote ${ }^{\circledR}$, facilitates creation of the list of references.

\section{Figures}

Radiological images and other figures illustrate the case report. Select the radiological examination images that best illustrate the disease and its radiological features. Highlight relevant findings by selecting a certain image section. The figures should have excellent quality, be in the format required by the journal (e. g. JPEG or TIFF), and be high resolution (e.g. 300 or 600 dpi) [18]. RöFo allows a maximum of 4 individual images or tables [11].

Each image should include a complete legend. Each one should begin with a sentence that summarizes the content of the figure. The legend must include the following features of the imaging method that was used: 1 ) Type of imaging method: conventional X-ray, MRI or CT; 2) Use of contrast agent; 3) Orientation of imaging: axial, coronal, sagittal; 4) In the case of MRI: specification of the MRI sequence; 5) In the case of CT: specification of the window setting (specification of Hounsfield units if applicable); 6) In the case of PET/CT: specification of the tracer with full length, e. g. [ $\left.{ }^{18} \mathrm{~F}\right] \mathrm{FDG}$ instead of just FDG. Arrows can be used to emphasize details and important findings.

Every image together with its legend should be able to stand on its own. The content of the figure legends is not repeated in the main text of the description of the case. Instead use the information in the figures to support the statements made in the main text.

\section{Conclusion}

Case reports are a valuable source of new and unexpected clinical information in medical literature. The uniqueness of the case, a careful and structured presentation, and a clear conclusion are essential for the successful publication of your own case report.

\section{Acknowledgment}

I would like to thank Prof. Dr. med. Gerhard Adam for his critical review of the manuscript and insightful comments. Thank you to Ingrid Krause for revising the text. I would also like to thank Herr Volker Niem vom Thieme Verlag for his constructive suggestions for improvement.

\section{Conflict of Interest}

No conflict of interest has been declared by the author(s).

\section{References}

[1] Jenicek M. Clinical Case Reporting in Evidence-Based Medicine. 2. Aufl Hodder Arnold Publication; 2001

[2] Cohen H. How to write a patient case report. Am J Health Syst Pharm 2006; 63: $1888-1892$

[3] Green BN, Johnson CD. How to write a case report for publication. J Chiropr Med 2006; 5: $72-82$

[4] Barnard CN. The operation. A human cardiac transplant: an interim report of a successful operation performed at Groote Schuur Hospital, Cape Town. South African medical journal = Suid-Afrikaanse tydskrif vir geneeskunde 1967; 41: $1271-1274$

[5] Nield LS. Writing case reports for the clinical literature: practical approach for the novice author. J Grad Med Educ 2011; 3: 445

[6] Gagnier JJ, Riley D, Altman DG et al. The CARE guidelines: consensusbased clinical case reporting guideline development. Deutsches Arzteblatt international 2013; 110: 603-608

[7] DeBakey L, DeBakey S. The case report. I. Guidelines for preparation. International journal of cardiology 1983; 4: 357-364

[8] Bannas P, Adam G, Bley TA. Instructions for original radiological research manuscripts. Fortschr Röntgenstr 2013; 185: 533- 538

[9] Kliewer MA. Writing it up: a step-by-step guide to publication for beginning investigators. American journal of roentgenology 2005; 185: 591 596

[10] Wells WA. Me write pretty one day: how to write a good scientific paper. The Journal of cell biology 2004; 165: 757-758

[11] RöFo. RöFo Autorenhinweise. In, Fortschr Röntgenstr 2016

[12] Spink C, Berliner C, Bannas P. Mediale Schenkelhalsfraktur bei KlippelTrenaunay-Syndrom: CT-Angiografie entscheidend für Therapie. [Article in German]. Rofo 2016; 188: 961 - 963. DOI: 10.1055/s-0042-108862. Epub 2016 Jun 14

[13] Bannas P, Adam G, Habermann C. Successful image guided implantation of a percutaneous gastrostomy in a previously operated Billroth II stomach. Fortschr Röntgenstr 2009; 181: 904-905

[14] Rosenfeldt FL, Dowling JT, Pepe $S$ et al. How to write a paper for publication. Heart, lung \& circulation 2000; 9: $82-87$

[15] Martyn C. Case reports, case series and systematic reviews. QJM 2002; 95: $197-198$

[16] http://pubs.rsna.org/pb/assets/raw/Radiology/PIA/Courses/03_Dos\% 20and\%20Donts_Kallmes.pdf

[17] Bordage G. Reasons reviewers reject and accept manuscripts: the strengths and weaknesses in medical education reports. Academic medicine: journal of the Association of American Medical Colleges 2001; 76: $889-896$

[18] Briscoe MH. Preparing Scientific Illustrations. 2nd ed New York: Springer; 1995 